\title{
Geology and Radiometric Survey of Ghumchi (Michika) Part of Hawal Massif NortheasternNigerian Basement Complex
}

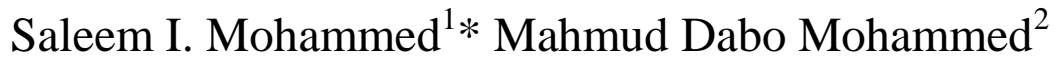 \\ Department of Geology Banaras Hindu University, Varanasi-221005, India
}

\begin{abstract}
Geology and radiometric survey of Ghumchi (Michika) part of Hawal massif NE Nigerian basement complex has been carried out, this lies at Longitude $13^{\circ} 23^{I} 00^{I I}$ to $13^{\circ} 30^{I} 00^{I I}$ E, Latitude $10^{\circ} 30^{I} 00^{I I}$ to $10^{\circ} 41^{I}$ $0 O^{I I} N$. The area is underlain by Basalt, Porphyritic Biotite Granite, Medium to coarse grained Granite, Migmatite Granite, Banded Gniess and, crush braccia catalasite and Mylonite along a fault zone. The dominant rock type in the mapped area is Porphyritic Biotite Granite and Migmatite Granite. The radiometric survey showed a high radiometric anomaly, which is observed Northward of the study area at a fault zone associated with Mylonite and Cataclasite, and this may be related to the concentration of radioactive elements such as Uranium, Thorium or Potassium. The radiometric data associated with each rock type has been recorded and analyzed so as to infer the exact rock type accommodating such high radiation. The data gathered shows that the Mylonite and Cataclasite found along the fault zone has the high radiometric anomaly with an average of 1962cps.
\end{abstract}

Keywords: Radiometric survey, Gamma radiation, Geological Mapping, Basement complex, Ghumchi.

\section{Introduction}

The area mapped is known as Ghumchi (MICHIKA) which is part of the Hawal Massif, basement complex of the Northeastern Nigeria. The work involved mapping the geology of the area, and measuring the radiometric Anomalies within the area of interest. And the study area covered about $25 \mathrm{~km}^{2}$ and lies within the coordinates, (Longitude $13^{\circ} 23^{\mathrm{I}} 00^{\mathrm{II}}$ to $13^{\circ} 30^{\mathrm{I}} 00^{\mathrm{II}} \mathrm{E}$, Latitude $10^{\circ} 30^{\mathrm{I}} 00^{\mathrm{II}}$ to $10^{\circ} 41^{\mathrm{I}} 00^{\mathrm{II}} \mathrm{N}$ ). Islam et al (1988) had mapped and divided the NE Nigerian Basement complex into four (4) which include the Mandara Mountain, Alantika Mountain, Shebshi Mountain and the Adamawa Massif where Hawal massif is considered as part of the Mandara Mountain. The Hawal massif is situated between the Cameroon highlands in the Benue trough. And This Hawal Massif is regarded as an extension of the Bamenda Massif that forms part of the Cameroon volcanic line in the eastern part of Nigeria (Ekwueme, 1993), it is bounded to the north by Chad basin and to the West by Gongola Basin and the Yola Arm of the Banue trough. The Hawal massif is made up of deeply dissected and rugged hills, which might extend up to about $800 \mathrm{~m}$ above mean sea level, and it is considered as one of the major Nigerian basement complex.

The principal aim of this research is mainly to examine the gamma radiation available within the study area, and to possibly locate those areas of high Radiation, and to monitor the radiometric anomalies present within the study area, and also to produce the radiometric map (IsoRad Map) of the study area after interpretation. The survey was achieved by pacing the entire study area using a traverse mapping technique thereby measuring the radiation and simultaneously mapping the geology of the area and also structural features, so as to examine the amount of radiation present in each rock type.

As mentioned out earlier that the survey is aimed at measuring the gamma radiation in the study area and this gamma radiation is common due to the radioactive decay of either Uranium (U), Thorium (Th), or Potassium (K) which might be available in the study area.

Radioactive decay also referred to as Radioactivity or a nuclear decay is an activity that takes place in an unstable atom where the nucleus loses its energy by emitting radiation. And a spontaneous discharge of these radiations [such as Alpha particles $(\alpha)$, Beta particles $(\beta)$, and Gamma rays $(\gamma$-ray)] from a rock material can be otherwise used in dating the age of the rocks, by the technique known as radiometric dating. A radiometric decay is considered as an unpredictable event that occurs in a random process at a single atom. According to quantum theory, it is not possible to predict when a particular atom will start decaying, because it takes place randomly.

Certain nuclei of atoms disintegrate spontaneously emitting $\alpha$-particles. This is the phenomenon of radioactivity. The nucleus is generally in an excited energy state after a $\beta$-emission and returns to its ground state with the emission of a further particle the $\gamma$-ray. In some rare instances emission of $\alpha$-particles is followed by $\gamma$-ray. The $\gamma$-ray is purely an electromagnetic radiation which does not alter the nuclear charge. As $\alpha$ - and $\beta$ particles passes through matter, they ultimately lose their energy due to collision and ionization with the matter which are then easily stopped by matter as they are emitted, leaving only $\gamma$-ray still active. (N.E Bassey, U. Kaigama, A. Oluwasegun 2013) 
Most gamma rays discovered at a surficial environment are due to the natural radioactive decay of Potassium (K), Thorium (Th), and Uranium (U). Gamma rays are large amount of electromagnetic radiations, characterized by smaller wavelength, high frequency and high energy. They have a penetrating capacity and can penetrate and travel about $35 \mathrm{~cm}$ through rock and hundreds of meters through air. Gamma rays have energy of definite characteristics, and measuring these energy permits the diagnosis of specific Potassium, Uranium or Thorium radiation.Radiometric survey is a geophysical technique often applied in studying the radiometric anomalies, Hence the technique is used as a basis of this research in measuring the gamma radiations.

\section{Instrumentation}

As stated out earlier that the research is aimed at determining the amount of gamma radiation in the study area and to possibly locate those areas with high radiation. All rocks and soils are radioactive to some extends and the survey does not only restricted to rock but include all the bare land in the area, hence the measurement of radioactivity across the earth surface constitute the method of geophysical exploration which are commonly done for radioactive minerals like uranium. This survey was made possible by using the following geological instruments;

a. Scintillometer for measuring gamma radiation.

b. G.P.S for taking the coordinate where radiation is recorded

c. Compass and clinometers for measuring dip and stike

d. Surfer 8 software for construction of ISORAD Map of the study area

Basically, the survey was done using the above mentioned instruments, and data was collected in a total of 104 stations by traversing the whole area of interest, measuring gamma radiations in each station using the scintillometer, and simultaneously taking the coordinates at each station with the help of the GPS.

The major instrument used in this research is the scintillometer, which is a detector of high energy radiations. This scintillation counter was used as a radiation survey meter. It is use in many mining industry to detect uranium in mineral samples. This particular meter was utilized to find desirable samples of radiation, rather than detect unwanted or harmful radiation in a work area. And since the survey is of radiometric survey, scintillation counter is chosen to be used for the survey.

When high energy atomic radiation are made incident on the surface coated with some fluorescent materials, then scintillations (flashes of light) are produced. These flashes of light (scintillations) are then detected with the help of photomultiplier tube that gives rise to electric pulse.

The scintillation counter is mainly of 3 different parts, namely;

1. Scintillator.

2. Photomultiplier.

3. Counter.

MAJOR PARTS OF THE SCINTILLATOR

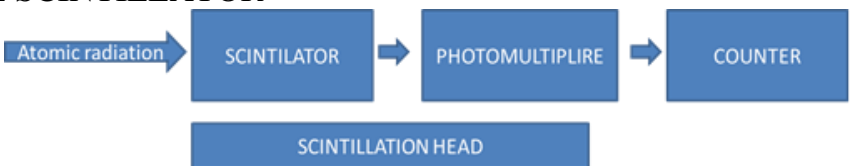

Scintillator together with the photomultiplier tube is collectively known as the scintillation head.

\subsection{THE SCINTILLATOR}

The scintillator is made from a single crystal; this single crystal should have some important characteristics in order to function properly as a scintillator,

1. First of all, it should be available in a proper form.

2. It should have an efficiency to convert incident radiation energy into light flashes.

3. The crystal should be transparent to light so that the maximum scintillations emitted by it can reach the photomultiplier tube.

4. The crystal should also have a suitable value of refractive index, so that the total internal reflection of light does not take place inside the crystal, otherwise light will be wasted.

5. The next important characteristics it should have is that the resolving cover of the crystal should be very high so that it should be able to distinguish radiations of different frequencies.

6. The crystal should be stable under stable experimental conditions.

Despite these required characteristics, many types of crystals are used as scintillators, some of them which include; 
a. Cesium iodite; used for the detection of gamma rays.

b. Zinc sulphide; used for the detection of heavy particles.

c. Organic phosphors; also detect gamma rays.

d. Xenon; is used for detection of heavy particles and also noted that it gives out ultraviolet radiation not visible light.

e. Thallium activated sodium iodine; which is also the most popular crystal that is used as scintillator, this is because it is more efficientcompares' with other crystal. But the major throwback in this crystal, is that it is hygroscopic in nature, i.e it can get spoiled due to moisture. Due to this reason, this crystal is sealed in an air tight $\mathrm{Al}$-can coated with $\mathrm{MgO}$ acting as a reflector.

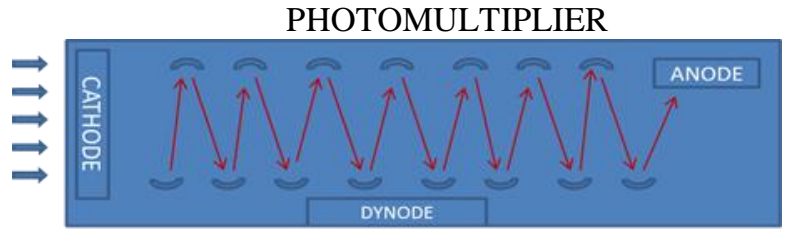

\subsection{PHOTOLTIPLIER TUBE}

The photomultiplier tube is an evacuated glass tube which has about ten electrodes properly arranged known as dynodes. These electrodes are specially designed and are properly positioned so that automatic focusing of electron can take place.

Each electrode has a photosensitive surface and performs two functions, namely;

a. Collection of photoelectrons coming from previous dynodes.

b. Emission of several low energy electrons due to incident electron.

The potential of dynodes is kept in the increasing order as we moved from cathode to anode, so that electrons emitted by a dynode get accelerated to the next dynodes.

So base on these, we can confidently say that a photomultiplier tube convert light into electrical energy.

\subsection{HOW THE SCINTILLATION COUNTER WORKS;}

1. The window made up of pyrex glass allows the radiations to pass and enter the scintillation counter

2. When high energy radiation strikes the crystal inside scintillators, short duration scintillations i.e flashes of light are emitted by the crystals.

3. The photos of light emitted by the scintillator are then made to strike the cathode of the photomultiplier tube through an optical coupling. These optical coupling is made up of a special fluid.

4. The photoelectrons emitted from the surface of the cathode are directed toward the first dynode that gives the secondary emission of electrons with about $0+$

5. The secondary electrons emitted from the surface of first dynode get accelerated towards the second dynode, which is at more potential in comparison to the first dynode.

6. This process is repeated up to the last dynode and electrons get much more multiplied in number. When they reach the anode, a high energy pulse is delivered to the counting device through the anode (the anode is also referred to as the PM tube)

7. The electric pulse from the PM tube is amplified and is then delivered to the counting device, after passing through a discriminator, where the discriminator removes the undesired noise pulse, and then the counting device now read and gives the amount of radiations in CPS equivalent to the intensity of electrons it receives.

Base on the above mentioned features the scintillometer is found to be the best instrument for this survey hence it is used.

\section{Methods}

In this context, the radiometric survey was carried out with the main aim of locating the areas of high radiation present within the study area. The survey began with a reconnaissance survey so as to trace the boundary of the interested area and to understand the extend of the study area using a topographic map, followed by gridding the topographic map. The important of gridding is to make the traversing easier and make it possible to cover the entire area and no place will be left unmapped. Then traversing technique was employed during the survey by pacing along each line of traverse with systematic and careful observation of each rock and its rate of radiation. Readings were recorded at every change in minutes of either longitude or latitude from the GPS, or where there is an increase or decrease in the amount of radiation during traversing. The scintillometer is equipped with an audio output which makes an audio sound corresponding to the amount of radiation present in the particular area as traversing goes on. Therefore, readings were also recorded where there is an increase or 
Geology and Radiometric Survey of Ghumchi (Michika) Part of Hawal Massif NE Nigerian ..

decrease in the sound of the scintillometer, were a total of 104 radiometric data was taken. While taking readings, the scintillometer was held firmly at approximately $1-1.5 \mathrm{~m}$ above the ground and also readings were recorded away from electric poles, vehicles or any other materials suspected to be radioactive in a little amount such as metals, so as to avoid interference by such materials which might end up giving wrong readings as precaution.

This radiometric survey was integrated with geological mapping of the area so as to study the amount of radiation present in each rock outcrop in the study area and to indicate precisely the rock type with high radiation which is accommodating such radioactive element. Rock samples were also collected as traversing is taking place to prepare a thin section for further laboratory studies, and software called SUFER 8was used to plot the radiometric map (ISORAD map) of the study area.

\section{Results And Discussion}

Radiometric data was recorded simultaneously with geological mapping of the study area which covers an extends of approximately $25 \mathrm{~km}^{2}$ and lies between the coordinates $\mathrm{N} 10^{\circ} 30^{\mathrm{I}}$ to $10^{\circ} 41^{\mathrm{I}}$, and $\mathrm{E} 13^{\mathrm{O}} 23^{\mathrm{I}}$ to $13^{\circ} 30^{\mathrm{I}}$. On the geology of the area as shown in Fig. 2 the Northern and southern parts of the mapped area can be interpreted differently. From the southern area, the SW part of the study area is occupied by porphyritic biotite granite with a Neogene to Recent Basalt that has erupted the Pre-Cambrian Basement during the Cenezoic era. And Migmatite Granite of Pre-Cambrian age covers SE part of the study area. A wrench Fault was also found to be cutting across the southern basement where the majority of the fault were trending along NW-SE direction as shown in the Rose diagram in Fig 6. While the Northern part of the study area is dominated by an undifferentiated weathered basement with some patches of Migmatite Granite and Porphyritic Biotite Granite at the Northwestern part of the study area. And in the Northern part of the study area, there exist another patch of Migmatite Granite at a Fault zone in a close association with Mylonite zone where a crushed Braccia Cataclisite zone faulted along the Mylonite zone where lateral movement later took place towards NE-SW. Other lithologies at the fault zone include Silicicated Braccia associated with Migmatite Granite.Fig 3.

Radiometric data was gathered from a diverse point with a total number of 104 data in the field and an ISORAD map Fig.4 is plotted using the collected data and shows contour lines representing areas of equal radiation. Closely spaced contour represents high radiation. Therefore, High radiometric anomaly was found in four different areas in Ghumchi which were located at coordinate N10 $40^{\mathrm{I}} 408^{\mathrm{II}} \mathrm{E} 013^{\circ} 27^{\mathrm{I}} 721^{\mathrm{II}}, \mathrm{N}_{10} 0^{\mathrm{O}} 40^{\mathrm{I}} 407^{\mathrm{II}}$ $\mathrm{E} 013^{\circ} 27^{\mathrm{I}} 719^{\mathrm{II}}, \mathrm{N} 10^{\circ} 40^{\mathrm{I}} 241^{\mathrm{II}} \mathrm{E} 013^{\circ} 27^{\mathrm{I}} 641^{\mathrm{II}}$ and N10 $40^{\mathrm{I}} 241^{\mathrm{II}} \mathrm{E} 013^{\circ} 27^{\mathrm{I}} 609^{\mathrm{II}}$ with a radiation of 1400,1750 , 2200 , and $2500 \mathrm{cps}$ respectively. One of the aims is to locate areas of high radiation and to measure the amount of radiation on every rock type so as to observe the rock associated with high radioactive concentration (table 1). As a result, high radiation is found at three different areas as shown in Fig 3. And are found along the fault zone associated with Mylonite and Cataclasite zone and the Migmatite Granite. However, radioactive elements were believed to be accommodated by these rocks at the fault zone.

Result from the thin section shows the present of variety of minerals belonging to feldspar group such as Microcline and Orthoclase Feldspar in all the rock samples except those in the fault zone possessing high radiation which was suspected to have been altered during the metamorphism along the fault zone. Chemically, Orthoclase Feldspar and Microcline contain certain percentage of $\mathrm{K}_{2} \mathrm{O}$ which are also radioactive to some extends, and this might be responsible for the lower radiations below 400cps observed within the study area.The fault zone is found associated with the uranium mineralization which was mineralized as a result of metamorphism that occur during fracturing and crushing along the fault zone that gives rise to the Cataclasite series of a crushed Braccia Cataclasite which is cohesive and random fabric with $0-10 \%$ proportion of matrix formed at approximately $5-6 \mathrm{~km}$ depth with grain size ranging between $0.5-5 \mathrm{~mm}$ which is known to be formed at a brittle-ductile shear zone and Mylonite formed by a ductile deformation mechanism which is cohesive and foliated, formed in a shear zone that were active under medium to high grade metamorphism with 50-90\% proportion of matrix at approximately $15 \mathrm{~km}$ depth. Fig. 1 (Sibson 1977). Table below shows the classification of fault rocks (adopted from Sibson 1977)

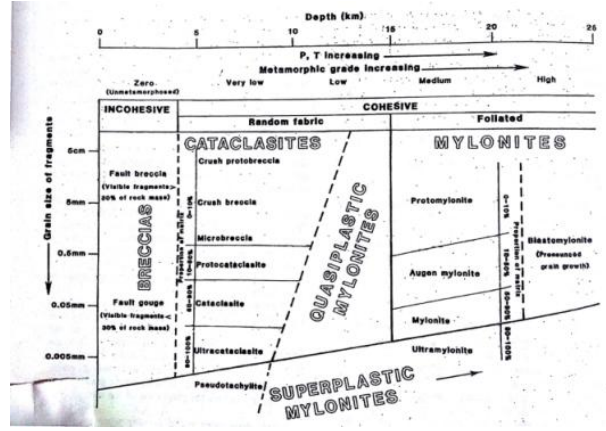

Fig 1. classification of fault rocks derived from quartzo-feldspathic Rock (Sibson 1977). 


\section{Conclusion}

The dominant rocks observed in the study area are mainly Porphyritic Biotite Granite, Migmatite Granite and Basalt Fig. 2. And a fault zone which makes up Cataclasite and Mylonite zones where the faulting are majorly trending NW-SE Fig. 6. Comparing the textural classification of faulted rocks (Sibson 1977) and the structural feature shown in Fig 1, it's concluded that Mylonite is first formed at depth of $15 \mathrm{~km}$ (according to Sibson 1977) and the tectonic activity that took place uplifted the Mylonite which during Upliftment, fracturing and crushing later took place and forms the Cataclasite at the brittle-ductile shearing zone. Brittle shear zone rocks are developed when fractures initiate, propagate, and coalesce in the rock (Blenkinsop and Rutter 1986). The anomalous concentration was discovered at the fault zone in Ghumchi as revealed from the radiometric map (ISORAD Map) Fig. 4 with an average radiation of $1962.5 \mathrm{cps}$ (table 1). It's also concluded that the concentration of radiogenic elements at the fault zone was due to low to medium grade metamorphism that took place which forms Cataclasite and Mylonite. Fig. 5 shows the histogram of the radiometric anomaly of the study area, high amplitude represents the fault zone at Ghumchi, while low amplitude represents other rocks and the undifferentiated weathered basement. This histogram shows that high radiation in the study area only occur at the fault zone. Each rock has radiation which differs from others, while some has low radiation, others has high radiation, and the rock with lowest radiation is the Porphyritic Biotite Granite and this may be due to the absence or low $\mathrm{K}_{2} \mathrm{O}$ as revealed from the microscopic study of the thin section with the absent of Orthoclase and microcline feldspars compared to others. The undifferentiated weathered basement has higher average radiometric count compared to the other rocks in the study area as shown in table 1. From Fig. 2, the undifferentiated weathered basement are found closed to the fault zone, as such they might be a weathered product originated from the fault zone possessing high radiometric count which might be related with the high radiation observed on the weathered basement.

\section{Acknowledgment}

I owe my profound gratitude to Dr. I.V Haruna of Geology Department Madibbo Adama University of Technology, Yola, Nigeria, who made this field work possible by providing the equipment such as Scintillometer for the survey. And I am also indebted to Prof. N.V.C Rao Banaras Hindu University, Varanasi, India, for a piece of advice and corrections.

\section{References}

[1]. Bassey N.E, Usman Kaigama, A. Oluwasegun (2013). Radiometric Mapping of Song Area and Environs, Hawal Basement Complex, Northeast Nigeria

[2]. Bell T.H, Etheridge M.A (1973). Microstructure of mylonite and their descriptive terminology.

[3]. Blekinsop T.G, Rutter E.H (1986). Cataclasite deformation of quartzite in moine thrust zone.

[4]. Ekweme, B.N (1993). An easy aproach to matamorphic petrology. University of Calabar press. P. 97-123.

[5]. Ekweme, B.N (1993). An easy aproach to igneous petrology. University of Calabar press. P. 31-36

[6]. Islam, M.R., Ostafiozuk, S. And Baba S. (1998). The Geology of the basement complex of Northen part of Mandara Hills Nigeria. Annals of Borno, vol. 6/8. University of Maiduguri.

[7]. Joseph .O. Coker, Amidu .O. Mustapha Victor Makinde Johnson .K. Adesodun (2013). Application of Radiometric Surveys to Delineate between Sedimentary Terrain and Basement Complex: A case study of Sagamu and Abeokuta, South Western Nigeria

[8]. N. O. Okoye, P. I. Olasehinde, I. A. Okunlola, Y. B. Alkali, T. A. Ako \& J. N. Chukwu (2012). Radiometric Survey as a Useful Tool in Geological Mapping ofWestern Nigeria

[9]. Oshin, I.O. and M.A., Rahaman, (1986) unranium favourability and mineralization in Northeastern Nigeria. Journ. of African earth science. PP167-175.

[10]. R.H Sibson (1977). Fault Rocks and Fault Mechanism. 


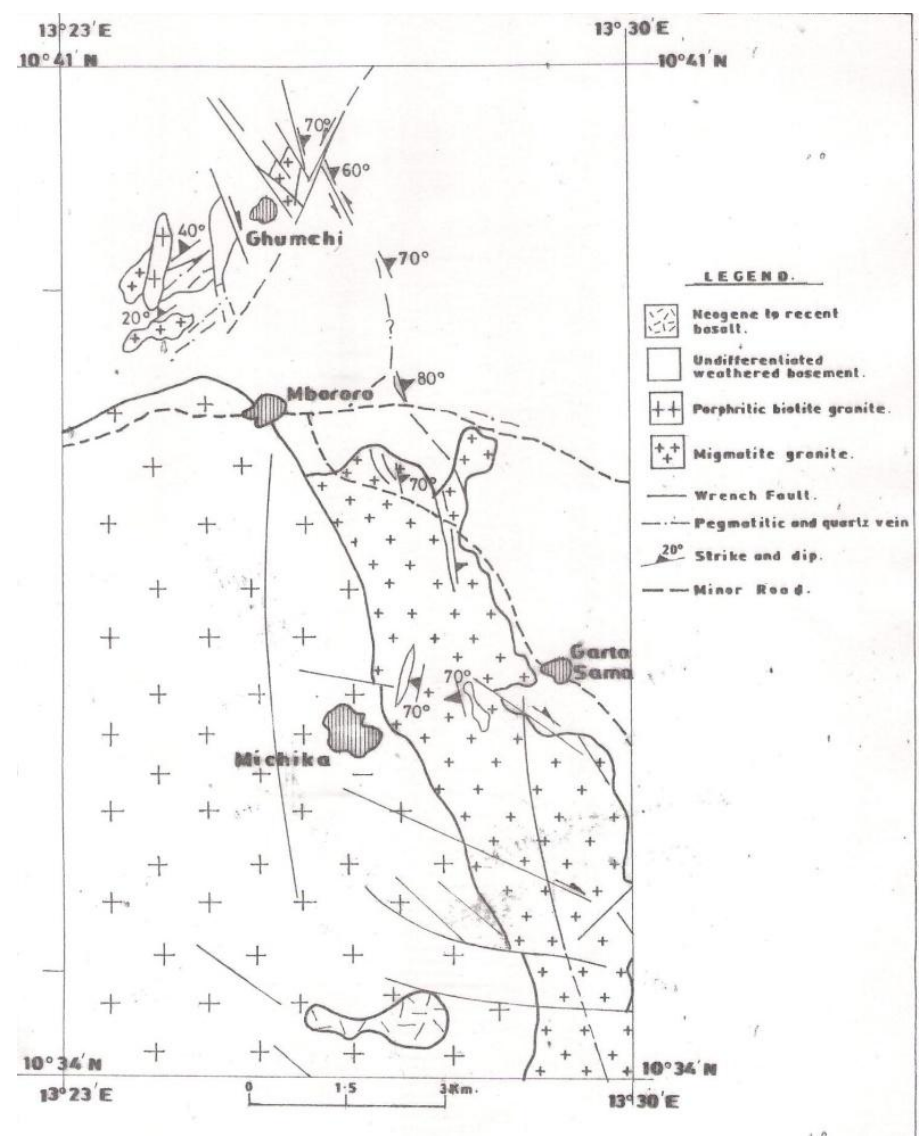

Fig. 2 Geologic Map of the study area.

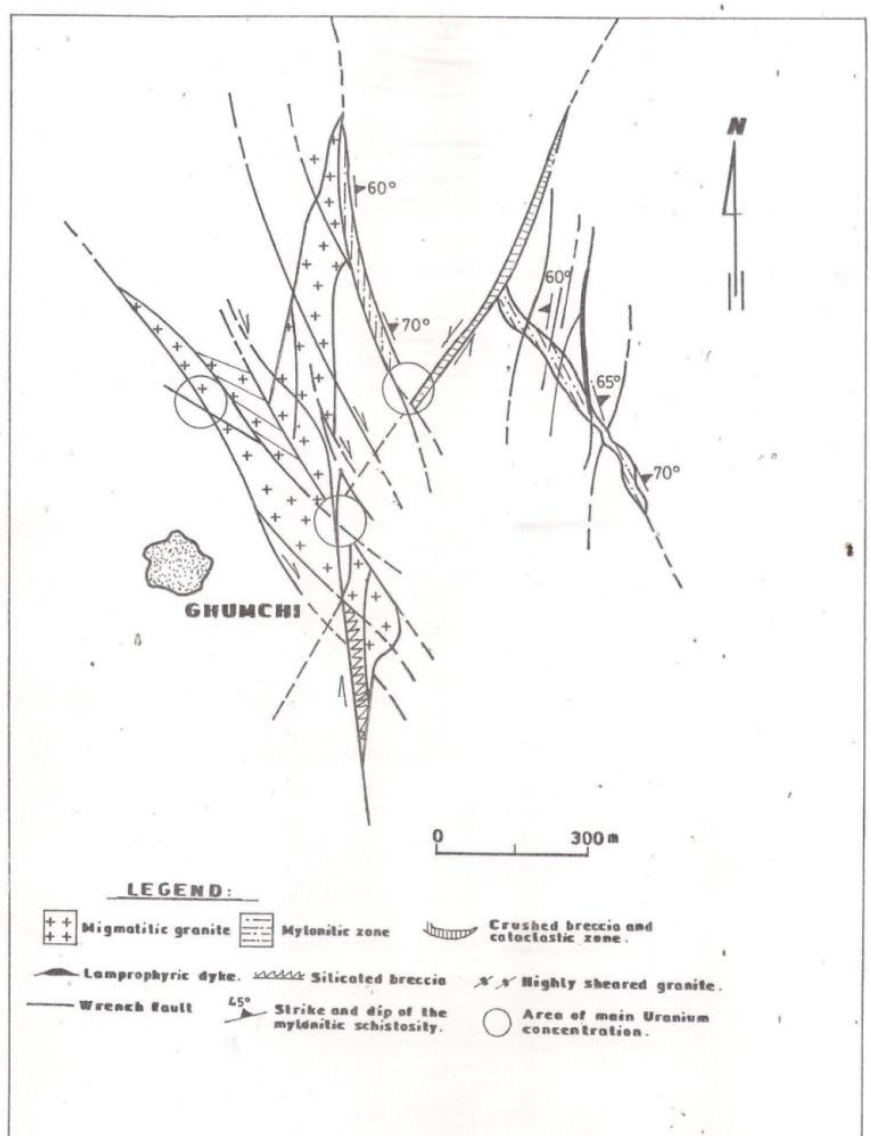

Fig. 3 Geological and structural feature at the fault zone of the study area 


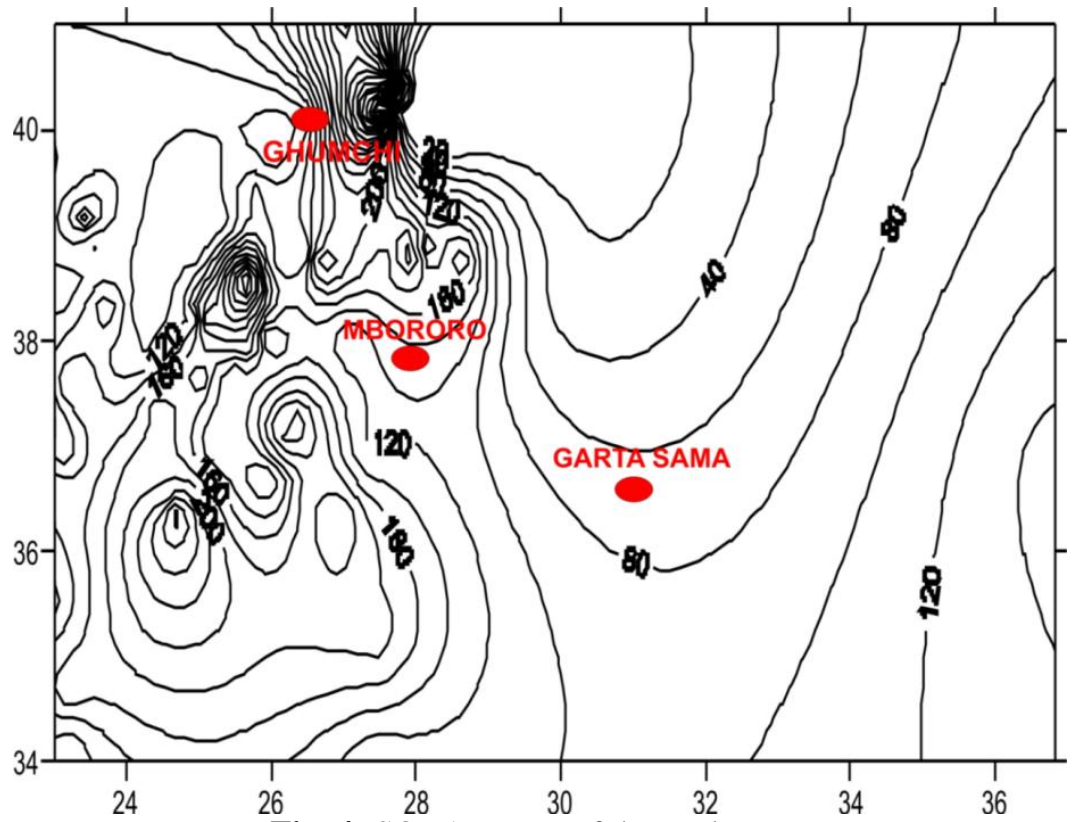

Fig. 4 ISORAD Map of the study area

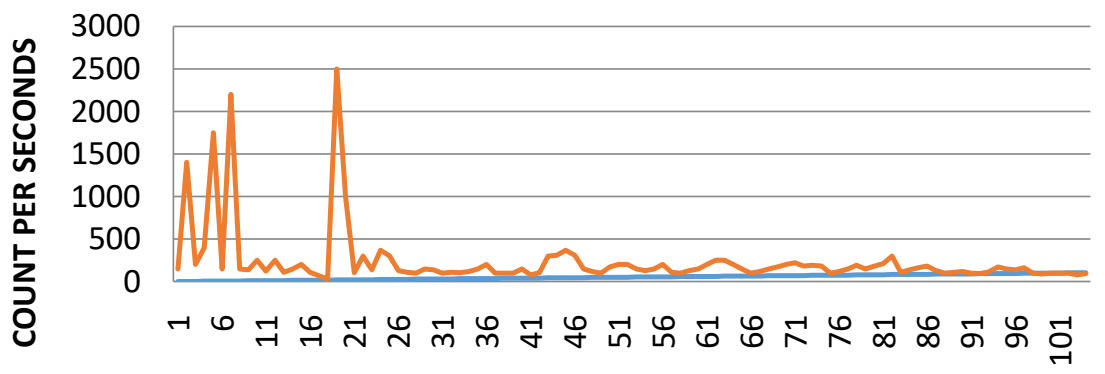

STATIONS

Fig. 5 the Histogram of the Radiometric anomaly in the study area

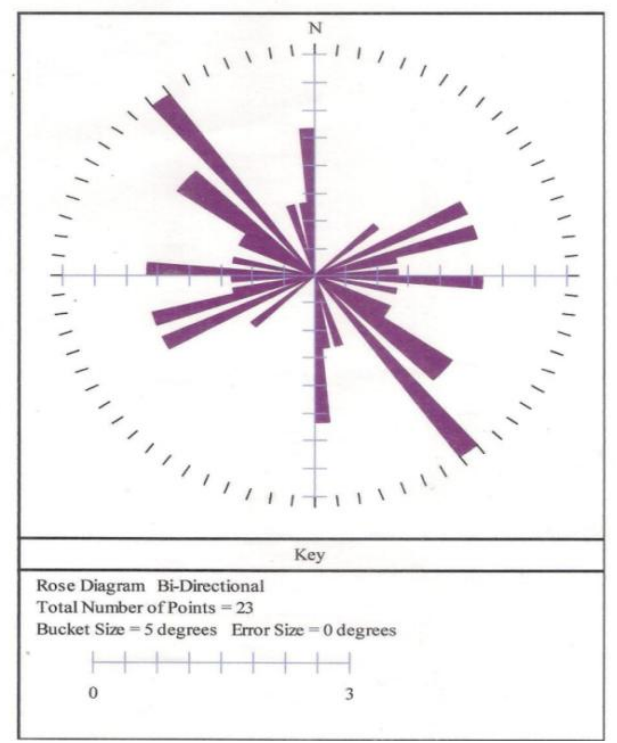

Fig. 6 Rose diagram of fault structure of the study area. 


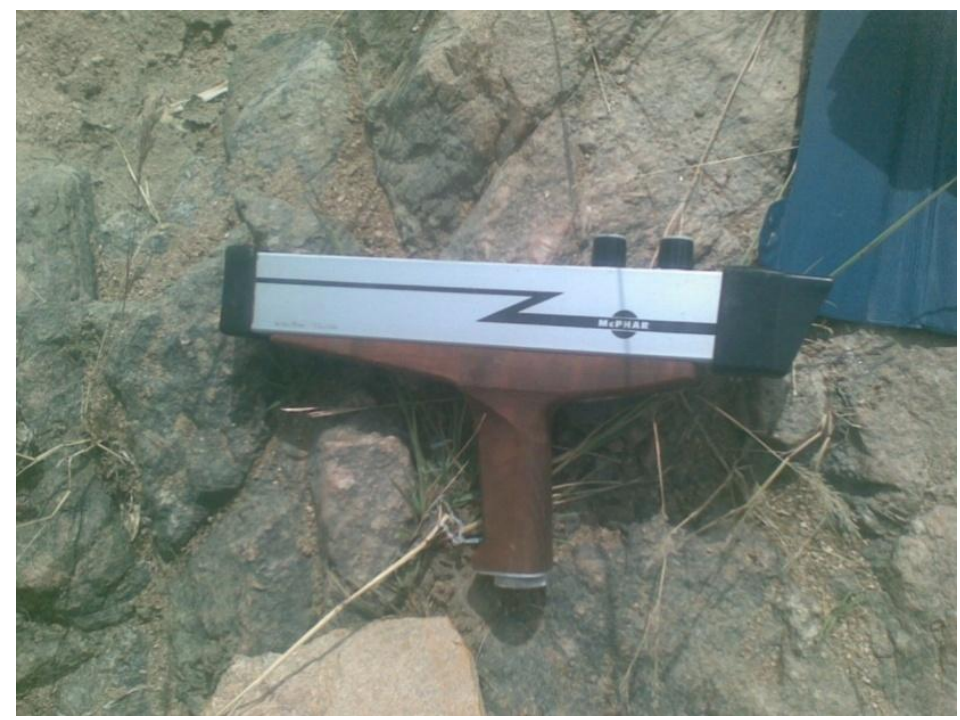

Fig 7. Scintillometer

Table 1. Radiometric data on each rock type.

\begin{tabular}{|c|c|c|c|c|}
\hline Rock type & Station number & Coordinate & Radioactivity (cps) & Average (cps) \\
\hline \multirow[t]{3}{*}{ Porphyritic Biotite Granite } & 58 & $\begin{array}{c}\mathrm{N} 10.37 .983 \\
\mathrm{E} 013.26 .033\end{array}$ & 100 & \multirow[t]{3}{*}{126.7} \\
\hline & 59 & $\begin{array}{l}\mathrm{N} 10.37 .706 \\
\mathrm{E} 013.25 .809\end{array}$ & 130 & \\
\hline & 60 & $\begin{array}{l}\text { N10.37.037 } \\
\text { E013.25.830 }\end{array}$ & 150 & \\
\hline \multirow[t]{4}{*}{ Migmatite granite } & 47 & $\begin{array}{l}\text { N10.36.653 } \\
\text { E013.27.258 }\end{array}$ & 150 & \multirow[t]{4}{*}{135} \\
\hline & 48 & $\begin{array}{l}\text { N10.37.006 } \\
\text { E013.27.253 }\end{array}$ & 120 & \\
\hline & 49 & $\begin{array}{l}\text { N10.38.067 } \\
\text { E013.27.087 }\end{array}$ & 100 & \\
\hline & 50 & $\begin{array}{l}\text { N10.38.816 } \\
\text { E013.27.608 }\end{array}$ & 170 & \\
\hline \multirow[t]{3}{*}{ Basalt } & 71 & $\begin{array}{c}\text { N10.36.382 } \\
\text { E013.27.008 }\end{array}$ & 220 & \multirow[t]{3}{*}{196.7} \\
\hline & 72 & $\begin{array}{l}\text { N10.35.691 } \\
\text { E013.27.501 }\end{array}$ & 180 & \\
\hline & 73 & $\begin{array}{l}\mathrm{N} 10.35 .243 \\
\mathrm{E} 013.27 .524 \\
\end{array}$ & 190 & \\
\hline \multirow[t]{4}{*}{$\begin{array}{l}\text { Mylonite and Cataclasite } \\
\text { zones }\end{array}$} & 7 & $\begin{array}{l}\text { N10.40.241 } \\
\text { E013.27.614 }\end{array}$ & 2200 & \multirow[t]{4}{*}{1962.5} \\
\hline & 2 & $\begin{array}{l}\text { N10.40.408 } \\
\text { E013.27.721 }\end{array}$ & 1400 & \\
\hline & 5 & $\begin{array}{l}\text { N10.40.407 } \\
\text { E013.27.719 }\end{array}$ & 1750 & \\
\hline & 19 & $\begin{array}{c}\mathrm{N} 10.40 .242 \\
\text { E01 } 3.27 .641 \\
\end{array}$ & 2500 & \\
\hline \multirow[t]{5}{*}{$\begin{array}{l}\text { Undifferentiated weathered } \\
\text { basement }\end{array}$} & 42 & $\begin{array}{l}\mathrm{N} 10.40 .146 \\
\mathrm{E} 013.26 .477\end{array}$ & 105 & \multirow[t]{5}{*}{279} \\
\hline & 43 & $\begin{array}{l}\mathrm{N} 10.40 .354 \\
\mathrm{E} 013.26 .776\end{array}$ & 300 & \\
\hline & 44 & $\begin{array}{l}\text { N10.40.864 } \\
\text { E013.27.030 }\end{array}$ & 310 & \\
\hline & 45 & $\begin{array}{l}\text { N10.40.974 } \\
\text { E013.27.053 }\end{array}$ & 370 & \\
\hline & 46 & $\begin{array}{c}\text { N10.41.000 } \\
\text { E013.27.088 }\end{array}$ & 310 & \\
\hline
\end{tabular}


Table 2. Radiometric data and coordinates of the study area.

\begin{tabular}{|c|c|c|c|}
\hline $\mathbf{S} / \mathbf{N}$ & LONGITUDE & LATITUDE & RADIOACTIVITY (CPS) \\
\hline 1 & 10.40 .477 & 013.27 .740 & 150 \\
\hline$\underline{2}$ & $\underline{10.40 .408}$ & $\underline{013.17 .721}$ & $\underline{1400}$ \\
\hline$\overline{3}$ & $\overline{10.38 .992}$ & $\overline{013.28 .008}$ & $\overline{200}$ \\
\hline 4 & 10.40 .481 & 013.37 .664 & 400 \\
\hline$\underline{5}$ & $\underline{10.40 .407}$ & $\underline{013.27 .719}$ & $\underline{1750}$ \\
\hline 6 & 10.40 .373 & 013.27 .703 & 150 \\
\hline$\underline{7}$ & $\underline{10.40 .241}$ & $\underline{013.27 .614}$ & $\underline{2200}$ \\
\hline 8 & 10.39 .990 & 013.27 .672 & 150 \\
\hline 9 & 10.39 .251 & 013.28 .015 & 140 \\
\hline 10 & 10.38 .831 & 013.27 .981 & 250 \\
\hline 11 & 10.38 .825 & 013.26 .527 & 125 \\
\hline 12 & 10.38 .763 & 103.26 .670 & 250 \\
\hline 13 & 10.38 .870 & 013.28 .084 & 110 \\
\hline 14 & 10.39 .079 & 013.28 .446 & 150 \\
\hline 15 & 10.38 .782 & 013.28 .665 & 200 \\
\hline 16 & 10.38 .723 & 013.29 .011 & 110 \\
\hline 17 & 10.37 .890 & 013.29 .297 & 70 \\
\hline 18 & 10.38 .407 & 103.30 .000 & 30 \\
\hline$\underline{19}$ & $\underline{10.40 .242}$ & 01 3.27.641 & $\underline{2500}$ \\
\hline 20 & 10.40 .241 & 013.27 .609 & 1000 \\
\hline 21 & 10.40 .236 & 013.27 .654 & 105 \\
\hline 22 & 10.40 .276 & 013.27 .624 & 300 \\
\hline 23 & 10.38 .716 & 013.25 .996 & 140 \\
\hline 24 & 10.38 .576 & 013.25 .665 & 370 \\
\hline 25 & 10.38 .273 & 013.25 .079 & 305 \\
\hline 26 & 10.38.219 & 013.24 .960 & 130 \\
\hline 27 & 10.37 .903 & 013.24 .153 & 110 \\
\hline 28 & 10.37 .812 & 013.23 .940 & 100 \\
\hline 29 & 10.36 .741 & 013.23 .005 & 150 \\
\hline 30 & 10.37 .147 & 013.23 .426 & 140 \\
\hline 31 & 10.38 .970 & 013.23 .518 & 100 \\
\hline 32 & 10.39 .537 & 013.23 .310 & 110 \\
\hline 33 & 10.40 .120 & 013.23 .259 & 105 \\
\hline 34 & 10.41 .000 & 013.23 .170 & 120 \\
\hline 35 & 10.39.289 & 013.23 .398 & 150 \\
\hline 36 & 10.39 .192 & 013.23 .434 & 200 \\
\hline 37 & 10.38 .387 & 013.24 .622 & 100 \\
\hline 38 & 10.38 .763 & 013.25 .056 & 100 \\
\hline 39 & 10.39 .043 & 013.25 .427 & 100 \\
\hline 40 & 10.39 .431 & 013.25 .753 & 150 \\
\hline 41 & 10.39 .795 & 013.26 .032 & 80 \\
\hline 42 & 10.40 .146 & 013.26 .477 & 105 \\
\hline 43 & 10.40 .354 & 013.26 .776 & 300 \\
\hline 44 & 10.40 .864 & 013.27 .030 & 310 \\
\hline
\end{tabular}


Geology and Radiometric Survey of Ghumchi (Michika) Part of Hawal Massif NE Nigerian ..

\begin{tabular}{|c|c|c|c|}
\hline 45 & 10.40 .974 & 013.27 .053 & 370 \\
\hline 46 & 10.41 .000 & 013.27 .088 & 310 \\
\hline 47 & 10.36 .653 & 013.27 .258 & 150 \\
\hline 48 & 10.37 .006 & 013.27 .253 & 120 \\
\hline 49 & 10.38 .067 & 013.27 .087 & 100 \\
\hline 50 & 10.38 .816 & 013.27 .608 & 170 \\
\hline 51 & 10.38 .279 & 013.25 .089 & 200 \\
\hline 52 & 10.37 .641 & 013.25 .090 & 200 \\
\hline 53 & 10.37 .642 & 013.25 .125 & 150 \\
\hline 54 & 10.37 .748 & 013.25 .510 & 130 \\
\hline 55 & 10.37 .770 & 013.25 .602 & 150 \\
\hline 56 & 10.37 .952 & 013.25 .747 & 200 \\
\hline 57 & 10.38 .043 & 013.25 .904 & 110 \\
\hline 58 & 10.37 .983 & 013.26 .033 & 100 \\
\hline 59 & 10.37 .706 & 013.25 .809 & 130 \\
\hline 60 & 10.37 .037 & 013.25 .830 & 150 \\
\hline 61 & 10.37 .075 & 013.26 .028 & 200 \\
\hline 62 & 10.37 .189 & 013.26 .181 & 250 \\
\hline 63 & 10.37 .240 & 013.26 .287 & 250 \\
\hline 64 & 10.37 .212 & 013.26 .206 & 200 \\
\hline 65 & 10.36 .818 & 013.36 .818 & 150 \\
\hline 66 & 10.36 .728 & 013.26 .728 & 100 \\
\hline 67 & 10.36 .603 & 013.36 .603 & 120 \\
\hline 68 & 10.36 .603 & 013.26 .148 & 150 \\
\hline 69 & 10.36 .513 & 013.26 .306 & 170 \\
\hline 70 & 10.36 .350 & 013.26.609 & 200 \\
\hline 71 & 10.36 .382 & 013.27 .008 & 220 \\
\hline 72 & 10.35 .691 & 013.27 .501 & 180 \\
\hline 73 & 10.35 .243 & 013.27 .524 & 190 \\
\hline 74 & 10.34 .998 & 013.27 .477 & 180 \\
\hline 75 & 10.34 .000 & 013.27 .402 & 100 \\
\hline 76 & 10.37 .000 & 013.25 .171 & 120 \\
\hline 77 & 10.37 .120 & 013.24 .982 & 150 \\
\hline 78 & 10.37 .409 & 013.24 .409 & 190 \\
\hline 79 & 10.37 .232 & 013.23 .981 & 150 \\
\hline 80 & 10.36 .920 & 013.24 .030 & 180 \\
\hline 81 & 10.36 .452 & 013.24 .546 & 210 \\
\hline 82 & 10.36 .365 & 013.24 .631 & 300 \\
\hline 83 & 10.35 .525 & 013.23 .001 & 110 \\
\hline 84 & 10.35 .201 & 013.23 .068 & 140 \\
\hline 85 & 10.34 .921 & 013.23 .130 & 160 \\
\hline 86 & 10.34 .690 & 013.23 .167 & 180 \\
\hline 87 & 10.34 .342 & 013.23 .209 & 130 \\
\hline 88 & 10.34 .034 & 013.23 .243 & 100 \\
\hline 89 & 10.34 .000 & 013.23 .293 & 110 \\
\hline
\end{tabular}


Geology and Radiometric Survey of Ghumchi (Michika) Part of Hawal Massif NE Nigerian ..

\begin{tabular}{llll}
\hline $\mathbf{9 0}$ & 10.34 .276 & 013.23 .295 & 120 \\
$\mathbf{9 1}$ & 10.36 .913 & 013.23 .125 & 100 \\
$\mathbf{9 2}$ & 10.37 .208 & 013.23 .000 & 95 \\
$\mathbf{9 3}$ & 10.37 .460 & 013.23 .022 & 115 \\
$\mathbf{9 4}$ & 10.37 .554 & 013.23 .216 & 170 \\
$\mathbf{9 5}$ & 10.37 .648 & 013.23 .408 & 150 \\
$\mathbf{9 6}$ & 10.37 .734 & 013.23 .575 & 140 \\
$\mathbf{9 7}$ & 10.38 .327 & 013.23 .744 & 160 \\
$\mathbf{9 8}$ & 10.38 .548 & 013.23 .403 & 100 \\
$\mathbf{9 9}$ & 10.38 .390 & 013.23 .115 & 90 \\
$\mathbf{1 0 0}$ & 10.39 .515 & 013.23 .000 & 100 \\
$\mathbf{1 0 1}$ & 10.38 .822 & 013.23 .822 & 100 \\
\hline $\mathbf{1 0 2}$ & 10.38 .819 & 013.24 .112 & 100 \\
$\mathbf{1 0 3}$ & 10.38 .322 & 013.24 .219 & 80 \\
$\mathbf{1 0 4}$ & 10.37 .974 & 013.24 .260 & 95 \\
\hline & & & 100 \\
\hline
\end{tabular}

